\title{
Ability of salivary biomarkers in the prognostic of systemic and buccal inflammation
}

\author{
Aida Gutiérrez-Corrales, Elena Campano-Cuevas, Gabriel Castillo-Dalí, Daniel Torres-Lagares, José-Luis \\ Gutiérrez-Pérez
}

Stomatology Department. Faculty of Dentistry. Seville, Spain

Correspondence:

Stomatology Department

Faculty of Dentistry. Seville, Spain

Address: C/ Avicena s/n. 41009

Seville, Spain

danieltl@us.es

Received: $12 / 02 / 2017$

Accepted: 08/03/2017

Gutiérrez-Corrales A, Campano-Cuevas E, Castillo-Dalí G, Torres-Lagares D, Gutiérrez-Pérez JL. Ability of salivary biomarkers in the prognostic of systemic and buccal inflammation. J Clin Exp Dent. 2017;9(5):e71622.

http://www.medicinaoral.com/odo/volumenes/v9i5/jcedv9i5p716.pdf

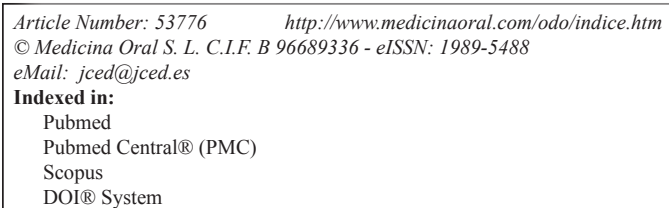

\begin{abstract}
Nowadays, there is a growing interest in using saliva as an alternative sample for the diagnosis, prediction and progression of several diseases. It has been established that some molecules found in saliva are related to oral inflammatory processes and systemic health status. Furthermore, it is known that saliva is crucial for the carrying out of different functions in the oral cavity and its role in the local modulation of inflammatory and immune response is being thoroughly studied by the health research community. The aim of this review is to analyze the most important biomarkers which have been utilized in biomedicine during the last two decades in order to establish a correlation between certain specific salivary biomarkers and systemic inflammation. Then, we discuss the utility of total proteins, immunoglobulin A and alpha-amylase as biomarkers for the prognostic of local inflammation after oral surgery.
\end{abstract}

Key words: Inflammation, salivary biomarkers, systemic disease, buccal surgery, total proteins, inmunoglobulin A, Alpha-amylase.

\section{Introduction}

During the last decades, salivary diagnostic approaches have been developed to diagnose and monitor oral diseases such as caries risk, microbial sepsis, inflammation and genetic pathologies like oral tumors and cysts. Buccal inflammatory biomarkers are biomolecules as proteins and derivatives which show an increase or de- crease in buccal processes coursing with inflammation. These biomarkers are commonly used in biomedicine to confirm the level and type of inflammation present in oral diseases. The local concentration of these proteins varies depending on habits, age, sex or the place where the sample was taken from (oral mucosa or another). The most common fluids used in inflammation prognos- 
tic assays are: Saliva, crevicular fluid and serum. Cytokines (TNF- $\alpha \&$ IFN- $\gamma$, IL-1,4,6,8,10), IgA, $\alpha$-Amylase, Cortisol and Total Proteins

are the most frequently used inflammatory salivary biomarkers in the recent decades and utilized in biomedical prognostic (1-5).

In the brain, cytokines are essential components of a signaling complex network in body inflammation. IL-1, IL-4, IL-6, IL-8 e IL-2 along with TNF- $\alpha$ and the IFN- $\gamma$ are the most habitual cytokines used like inflammatory salivary biomarkers since they have become in the most influential molecules in the risk detection site of the patient, also for other inflammatory chain factors activation and for the proper inflammation process (6-9). In addition, the alpha tumor necrosis factor is a very important protein cytokine for neutrophils and other blood cell activation in acute inflammatory process into sepsis and oral diseases like periodontitis and its diagnosis (6, 10). Furthermore, the Gamma interferon is also a protein cytokine that is secreted by T-cells to perform macrophages activation in oral diseases like periodontitis in the inflammation process (11).

Focused on $\operatorname{Ig} \mathrm{A}$, it is an immunoglobulin type protein like a biomarker of immunological activity which is presented in seromucinous fluids as the primary defense against pathogens. The level of this protein increases significantly in case of infectious diseases, as well as IgG and IgM such in case of periodontitis, showing a positive correlation between the severity of periodontal, gingival damage and IgA concentrations. These concentrations are crucial in antibacterial, antifungal and antiviral process (12-17).

The alpha amylase is an enzyme of polysaccharides degradation which is used on the treatment and in the prognostic of inflammatory diseases, in actinomycetems infection and against some bacteria as the ones that cause caries $(3,18-22)$. The AASH, especially for its high concentration, has been used as a biomarker. Its concentration is $1080 \pm 135.6 \mathrm{IU}$ or $476 \pm 120 \mathrm{mg} / \mathrm{ml}$ in adults.

Nevertheless, all the proteins concentration is the sum of the levels of each protein into the oral fluids and they are also quite relevant and significant in inflammation process, in clinical analysis and in the diagnostic of some diseases which show a linear increase correlation in patients with high advanced age and caries $(12,23)$. However, cortisol is an anti-inflammatory hormone that is used in several assays but its results present several variances between sex, day and type of assay and they are not always statistically significant $(4,12,20)$. Others buccal salivary biomarkers are involved in oral fluids: Protein-2, Protein-3B, Chaperokines, Cystatin, Lysozime-C, Lipocalin, BPI, Collagenases MMP-8, PLUNC, Mucins, Peroxidases, Prolin-rich Protein, Chromogranine-A, LDH, Reactive Protein-C (18-20,24,25).
The advantage of using saliva as a diagnostic means is that their sampling is easy and non-invasive but this potential has not been fully exploited, due to the lack of some techniques to detect components that are in less concentration. However, it is expected that with the advancement of bioinformatics, genomics and proteomics, saliva becomes increasingly a study tool, due to its ability to reflect conditions of oral and systemic health $(26,27)$.

It is obvious that after any surgery in the oral cavity, it appears in varying degrees postoperative swelling as physiological response of the organism; the preventive philosophy of such symptoms is based on anticipating to the appearance for trying to minimize them. While postoperative orofacial pain is a direct result of the damage caused by the surgery and the body's response to it, we should not forget that pain perception varies with each patient based on certain factors. The importance of the anxiety and the degree of stress of the patient in the postoperative pain perception, has been widely studied by different authors, who defined that anxiety can lengthen the time of the intervention by inducing greater pain and inflammation and it can also increase the intensity of both postoperative symptoms possibly by reducing the threshold of pain tolerance (28).

Saliva concentrations of total protein, immunoglobulin A and alpha-amylase vary when inflammation occurs within infectious processes of the oral cavity. Similarly we seek to relate the preoperative values of those salivary markers with the postoperative ones, which will allow us to establish a prognostic value of inflammation that will occur in the postoperative period. Through the availability of studies to increase knowledge of the salivary prognostic factors related to inflammation will help to improve the quality of the healthcare. Furthermore, this study proposes innovative cooperation of two areas of health sciences: oral surgery and molecular biology (29).

\section{Discussion}

In recent years, several analytes in saliva have been evaluated as biomarkers for many diseases including: cancer $(30,31)$, type II diabetes $(32)$, infections $(33,34)$, pulmonary (35) and cardiovascular diseases (36), among others. These findings allow facilitating the diagnostic of systemic illness because saliva is a non-invasive and easy-to-use sample.

Abnormal cortisol rhythms before epithelial ovarian cancer treatment has been associated with higher inflammation in the tumor zone and decreased survival of patients. In this sense, nocturnal concenrations level has been proposed as a measure of the hypothalamicpituitary-adrenal (HPA) dysfunction that occurs in this kind of cancer and an indicator of disease severity. In this study, an association between ascites pro-inflamma- 
tory cytokine IL-6 and salivary cortisol was observed; indicating night concentration may be an efficient biomarker for measuring HPA function in ovarian cancer population (37).

Other researchers have focused on secretory proteins as cancer biomarkers because they are closely related with the malignant tumor angiogenesis, differentiation, invasion and metastasis process (38). Although most studies have been performed to identify such biomarkers in serum (38-40), there are some of them interested in identifying saliva secretory proteins that could be used as cancer biomarkers. Shiiki et al. have examined levels of Prostate-specific Antigen (PSA) in saliva and its association with serum PSA in two groups of patients with prostate adenocarcinoma (PA), a low-serum PSA concentration group and a high-serum PSA concentration group with high risk of recurrence or metastasis. They concluded that saliva PSA may be a useful PA biomarker in those cases in which patients have recurrent or metastatic PA, as in this situation saliva PSA concentration is associated with blood PSA (41). In this same field, Streckfus et al. suggest salivary proteins as biomarkers for carcinoma in situ of the breast (DCIS). They studied saliva specimens from three groups of women (ten healthy subjects, ten patients diagnosed with a benign breast tumor and ten women diagnosed with DCIS). Their results revealed that protein-by-products of oncogenic expression appear in the saliva of breast cancer patients but not in healthy controls (42).

In the other hand, there are several antigens that are expressed in tumor cells but not in normal ones or, at least, not at that high concentration so these tumors associated antigens might act as tumor associated antigens. In this situation, the immune system would prepare for recognizing tumor cells (43). At this point, it is reasonable to think that several antibodies can act as predictors in the diagnosis of this malignancy and, in fact, protein p53 antibodies IgA and IgG have been found in the serum and saliva of patients who overexpressed p53 in their tumor tissues, demonstrating that the detection of these antibodies could identify oral squamous cell carcinoma with p53 mutations, which occurs in $50 \%$ of cases $(44,45)$.

In coronary heart disease, several biomarkers can be detected in saliva and its levels vary from those measured in healthy individuals. In this sense, changes in concentration of active matrix metalloproteinase (MMP)-8, creatinine phosphokinase, troponin I have been observed in saliva and these altered concentrations of biomarkers correlates with serum concentration, so again saliva results a useful sample for diagnosing systematic diseases (46-48).

In Acute Myocardial Infarction (AMI), fast diagnostic is essential for optimal therapy to be offered because every minute of delay in treating AMI increases the mortality rate (49). Saliva contains thousands of biomolecules that are derived from the local capillary bed (50), which makes saliva a potential source for a rapid diagnosis of AMI in the emergency setting (51-53). In the research of specific salivary biomarkers with clinical potential for the assessment of AMI, C-reactive protein, $\mathrm{SCD} 40 \mathrm{~L}$ and CK-MB, as well as creatinine phosphokinase, TnT, and TnI resulted useful diabetes (32).

As well as others systemic diseases, inflammation is a condition in which many studies have focused. Among them a small number of studies have investigated inflammation markers in saliva as they are altered in response to an acute stressor. In this sense, several studies have proposed salivary biomarkers to identify different stress status. Among these, salivary levels of pro-inflammatory cytokines and anti-inflammatory cytokines have resulted to be increased in those subjects exposed to a stress situation (54-56).

In this field, Mahmood and Ibrahim, 2013, have demonstrated increased levels of pro-inflammatory interleukin 1-beta in saliva from 24 healthy students when they were subject to examination stress. These results support those found by Usui et al., 2012, when testing saliva from 10 physically active participants exposed to a 60 minute exercise stressor. In this case, levels of IL$1 \mathrm{~b}$, IL-6 and TNF-alpha were significantly higher during completion than those measured during the resting session. Besides, elevation in TNF-alpha and IL-2 salivary levels have been detected in University professors 120 after exposures to social-cognitive stressors (56). The same approach was observed when testing concentrations of anti-inflammatory cytokines IL-4, in saliva samples taken from individuals before and after stress conditions.

Others biomarkers have been assayed not because it is useful as inflammation indicators, but as direct markers of immune system status. This way, salivary immunoglobulin A ( $\operatorname{sg} \mathrm{A})$ has been measured as a predictor for immunity variations caused by stress (57).

The immune response has been proposed as a mechanism of protection, a mediator of injury, and a need for repairing tissues in periodontal disease. Immunoglobulins have been recognized as elements in human inflamed gingiva. Brandtzaeg and Kraus studied the most striking difference between saliva samples in healthy and inflamed gums and it was found a predominant increase in the number of plasma cells containing IgA using the immunofluorescence method (58).

Many studies have been published about the concentration of $\operatorname{IgA}$ in saliva but data are extremely confusing. The concentration of IgA in samples of whole saliva or mainly of the parotid (59), has been discussed in different investigations, linking them with oral pathological processes, obtaining different results due to the influence of various factors such as the maintenance in cold, saliva collected at rest or after some kind of stimulation, or 
stress to which the patient has been undergone. Several studies about salivary IgA concentration was analyzed in young patients with oral inflammation to see if there were significant differences between saliva samples collected at rest or stimulated (60). According to scientific evidence, the IgA concentrations is higher in parotid than mixed saliva and after stimulation, the concentration of salivary IgA decreases in both types of saliva $(3.1 \pm 2.2 \mathrm{mg} / \mathrm{dl}$ in mixed saliva and $6.8 \pm 5 \mathrm{mg}$ dl parotid salivary).

Similarly, another study measured the concentration of $\operatorname{IgA}$ in mixed saliva and of the parotid exclusively (61) in individuals with gingival inflammation as a consequence of an infection, obtaining in both samples a similarity in the concentration of IgA. This could be due to prolonged activity of bacterial antigens, the stimulation of IgA production, the increase of absorption of combined antigen through inflamed gingiva or glandular local production of IgA among other factors (58).

In addition, investigation has been interested in the use of salivary biomarkers for detecting type-2 Diabetes. Rao et al., 2009, used whole saliva samples from control and type-2 diabetic individuals to identify such biomarkers. They found 65 proteins that were greater than 2 -fold more abundant in type- 2 diabetes samples compared to control specimens, providing a view of saliva potential utility in detecting and monitoring

In recent decades, there has been considerable progress in the understanding of the genetic and biochemical properties of the major salivary proteins. Salivary proteins and glycoproteins are the major components of the biofilm, whose function is to keep moisture and act as a barrier to protect the teeth and structures around the teeth (23).

There are numerous defense proteins in saliva. Although some of these molecules are present in very low concentrations, its effects are additive and synergistic, resulting in an efficient molecular defense network of the oral cavity. Moreover, the local concentrations of these proteins near mucosal surfaces (transudate mucosa), periodontal groove (fluid crevicular gingiva) and oral wounds and ulcers (transudate) can be much larger, and often reinforced by immune reactions and inflammatory diseases of the oral mucosa $(62,63)$. Some defense proteins, such as salivary immunoglobulin are involved in innate and acquired immunity. Cationic peptides and other defense proteins such as lysozyme, salivary amylase, cystatins, mucin, peroxidases, and statherin, among others, are primarily responsible for innate immunity. Salivary flow and concentration of various inorganic and organic components may vary by state of health, age, medication, etc (64).

It was observed some alterations in the biochemical composition of saliva in patients with oral leukoplakia and cancer which could be attributed to salivary gland dysfunction caused by alcohol and snuff due to chronic alcohol intake is associated with significant changes in the secretion the parotid saliva and its composition. The alcohol consumption causes a decrease in the flow of whole unstimulated saliva and therefore there is also a lower total protein content, alpha-amylase and electrolytes (63).

The human salivary $\alpha$-amylase (AASH) is the saliva protein found in greater concentration and has enzymatic activity, which catalyzes the links $\alpha-1,4$-glycosidic of starches and carbohydrates. Also it plays an important role in the colonization and metabolism of the bacteria that lead to plaque formation. In solution, this protein binds with high affinity to a select group of oral streptococci, which can assist in debugging or bacterial cleaning the oral cavity (63). It is produced locally in salivary gland and its secretion is controlled by the autonomic nervous system, which has been proposed as a biomarker for the activity of this system. In general, direct measurement of its activity in the oral cavity has allowed its partnership with states of pain, stress and disease. As noted above, the presence in the saliva of endogenous substances in human serum allows saliva be potentially used to diagnose some diseases like oral cancer and breast cancer, periodontal disease, Sjögren's syndrome, among others (65).

The great variability concentration of salivary proteins has been used to characterize the state of disease of some individuals and is known as biomarkers. According to the National Institute of Health in the United States, this term is given to a quantitatively measurable biological parameter that serves as an indicator of the health and physiological assessments related to pathogenic processes, environmental exposure and the diagnosis of disease or response to drug therapy or therapeutic intervention (66).

Currently, the third molar surgery is the most common surgical technique performed in the oral cavity. This often triggers an inflammatory process which is characterized by symptoms as pain of the operated area, soft tissue swelling with subsequent facial deformity, and sometimes a degree of lockjaw associated. Normally, postoperative requires an average of seven days of labor inactivity primarily associated with the inflammation that occurs. Therefore, trying to minimize any secondary symptoms after oral surgery without interfering in the physiological process of inflammation following surgical trauma should be a primary objective.

These symptoms are terribly uncomfortable for the patient, depending on the intensity of multiple factors such as the complexity of the surgery, the duration, the surgeon's technique, the existence of iatrogenic, etc. The minimization of such manifestations directly affects the satisfaction of the treatment, improves the life quality of the patient and also reduces the fear to these surgical interventions. The concepts to control postoperative symptoms have changed substantially over the last years as it has advanced the understanding of the pathophysio- 
logical basis of pain and inflammation as well as the mechanism of action and pharmacodynamics of analgesics and anti-inflammatory used in their treatment although nowadays there is more emphasis on the importance of preventing both pain and inflammation $(67,68)$.

On the one hand, Holland (69) and Puche et al. (70) defend that the degree of postoperative facial swelling is unpredictable and it depends on the different response of the patient to the surgical trauma. Seymour et al. (71) and Meechan and Seymour (72) argue that the severity of pain varies from patient to patient and it does not seem to be related with the degree of impaction and surgical trauma required to remove the tooth. On the other hand, Capuzzi et al. (73), who claim that postoperative inflammation is predictable because it depends mainly on surgical aggression among other factors.

Due to understand the way of utilize these biomarkers, we presents above the most common material and methods used to detect and measure biomarkers in saliva:

- ELISA

- Bioplex-Luminex

- FC (Flow Citometry)

- BRADFORD
- MRD

- IFD

- MANCINI

- LORRY

- MS (Mass Spectrometry)

All the same, the enzyme immunoassay (ELISA), direct immunofluorescence and flow cytometry $(\mathrm{CF})$ are the most common methods used in molecular biology for prognostic analysis. In this sense, samples can be diluted and resuspended or not in the biomedical laboratory after homogenized by vortex. Then, it is possible to make an ELISA immunoassay using a 96 wells plate to proceed the samples analyze using a plate lector which usually get a standard curve in order to interpolate results currently and finally noise balanced using the "zero" controls and placebo. Looking to a future point of view, salivary fluids seems to be a new efficient diagnose and prognostic method in biomedicine and oral diseases at early state. It is also necessary to remark the new advanced technique in biomarkers measurement; The Detection Chips, which bring the possibility of analyze million samples simultaneously and more analytes per sample (Table 1).

Table 1: Table of the principal diseases salivary biomarkers.

\begin{tabular}{|c|c|c|}
\hline Disease & Saliva Biomarker & Reference \\
\hline \multicolumn{3}{|l|}{ Cancer } \\
\hline Epithelial ovarian cancer & Night Cortisol & Schrepf et al., (37) 2015 \\
\hline Prostate adenocarcinoma & Prostate-specific Antigen (PSA) & Shiiki et al., (41) 2011 \\
\hline Breast carcinoma & Proteins of oncogenic expression & Streckfus et al., (42) 2008 \\
\hline $\begin{array}{l}\text { Oral squamous cell } \\
\text { carcinoma }\end{array}$ & Protein p53 antibodies IgA and IgG & Warnakulasuriya et al., (44) 2000 \\
\hline \multicolumn{3}{|l|}{ Cardiovascular } \\
\hline Acute Myocardial Infarction & Matrix Metalloproteinase (MMP)-8 & Buduneli et al., (46) 2011 \\
\hline Acute Myocardial Infarction & Creatine Phosphokinase & Mirzaii-Dizgah et al., (47) 2011 \\
\hline Acute Myocardial Infarction & Troponin I & Mirzaii-Dizgah et al., (48) 2013 \\
\hline Acute Myocardial Infarction & $\begin{array}{c}\text { Troponin I, PCR and B-type natriuretic } \\
\text { peptide. }\end{array}$ & Sabatine et al., (52) 2002 \\
\hline Acute Myocardial Infarction & C-reactive protein & Miller et al., (53) 2014 \\
\hline \multicolumn{3}{|l|}{ Metabolic } \\
\hline Type-2 Diabetes & 65 Proteins & Rao et al., (32) 2009 \\
\hline \multicolumn{3}{|l|}{ Stress } \\
\hline Inflammation & IL-1-beta & Mahmood and Ibrahim, (54) 2013 \\
\hline Inflammation & IL-1b, IL-6 and TNF-alpha & Usui et al., (55) 2012 \\
\hline Inflammation & IL-2, IL-4 and TNF-alpha & Filaire et al., (56) 2010 \\
\hline Immunity variations & $\operatorname{IgA}$ & Tsujita et al., (57) 1999 \\
\hline
\end{tabular}




\section{Conclusions}

- IgA and Cytokines like IL's and TNF- $\alpha$ \& IFN- $\gamma$ seem to be the most used biomarkers used in diagnostic and prognostic of oral diseases like Periodontitis and caries risk through immunoassays.

- A-amylase and Total proteins are also two biomarkers commonly utilized in prognostic of oral diseases by ELISA or IFD analysis.

- Provide objective data relating to changes sequentially in the studied concentration of three components of saliva: total protein, immunoglobulin A and alpha-amylase in response to oral surgery, improving the understanding of the pathophysiology of saliva after surgery in the oral cavity.

- Provide criteria for establishing clinical protocols for the treatment of postoperative inflammation in patients undergoing oral surgery, taking into account the changes detected in the concentration of salivary biomarkers studied, thereby contributing to improved quality assistance practiced in the most prevalent oral cavity surgery.

\section{References}

1. Demetriou N, Drikos G, Bambionitakis A. Relation between gingival fluid and mixed and parotid salivary IgA. J Periodontol. 1978;49:64-6.

2. Malon RS, Sadir S, Balakrishnan M, Córcoles EP. Saliva-based biosensors: noninvasive monitoring tool for clinical diagnostics. Biomed Res Int. 2014;2014:962903.

3. Lamby CP, Gomez OL, Jaramillo L. Salivary a -Amylase : Relation with Dental Caries and Health in General. Univ Odontol. 2013;32:93101.

4. Sadi H, Finkelman M, Rosenberg M. Salivary cortisol, salivary alpha amylase, and the dental anxiety scale. Anesth Prog. 2013;60:4653.

5. Spielmann N, Wong DT. Saliva: Diagnostics and therapeutic perspectives. Oral Dis. 2011;17:345-54.

6. Castro CE, Koss MA, López ME. Biochemical markers of the periodontal ligament. Med Oral. 2003;8:322-8.

7. Miller CS, King CP, Langub MC, Kryscio RJ, Thomas MV. Salivary biomarkers of existing periodontal disease: a cross-sectional study. J Am Dent Assoc. 2006;137:322-9.

8. Salvi GE, Franco LM, Braun TM, Lee A, Rutger Persson G, Lang NP, Giannobile WV. Pro-inflammatory biomarkers during experimental gingivitis in patients with type 1 diabetes mellitus: A proof-of-concept study. J Clin Periodontol. 2010;37:9-16.

9. Tsai CC, Ku CH, Ho YP, Ho KY, Wu YM, Hung CC. Changes in gingival crevicular fluid interleukin-4 and interferon-gamma in patients with chronic periodontitis before and after periodontal initial therapy. Kaohsiung J Med Sci. 2007;23:1-7.

10. Garrido Flores M, Ordenes Vitali T, Segú Cabrera C, Baeza Paredes M, García-Sesnich J, Hernandez Rios M. Asociación entre niveles de TNFalpha en fluido crevicular gingival de dientes con periodontitis apical asintomática. Rev Clín Periodoncia Implantol Rehabil Oral. 2011;4:130-3.

11. Dutzan N, Vernal R, Hernandez M, Dezerega A, Rivera O, Silva $\mathrm{N}$, et al. Levels of interferon-gamma and transcription factor T-bet in progressive periodontal lesions in patients with chronic periodontitis. J Periodontol. 2009;80:290-6.

12. Arroyo-Morales M, Olea N, Ruíz C, del Castilo J de D, Martinez M, Lorenzo C, et al. Massage after exercise--responses of immunologic and endocrine markers: a randomized single-blind placebo-controlled study. J Strength Cond Res. 2009;23:638-44.

13. Ben-Aryeh H, Naon H, Szargel R, Horowitz G, Gutman D. The concentration of salivary $\mathrm{IgA}$ in whole and parotid saliva and the effect of stimulation. Int J Oral Maxillofac Surg; 1986;15:81-4.
14. Favre L, Spertini F, Corthésy B. Secretory IgA possesses intrinsic modulatory properties stimulating mucosal and systemic immune responses. J Immunol. 2005;175:2793-800.

15. Gross A, Setterstrom JA, D’Alessandro SM, Van Swol RL. Immunoglobulins in periodontal tissues. I. Concentrations of immunoglobulins in normal and inflamed gingiva. J Periodontol. 1979;50:581-5.

16. Güven O, De Visscher JG. Salivary IgA in periodontal disease. J Periodontol. 1982;53:334-5.

17. Kugler J, Hess M, Haake D. Secretion of salivary immunoglobulin A in relation to age, saliva flow, mood states, secretion of albumin, cortisol, and catecholamines in saliva. J Clin Immunol. 1992;12:45-9. 18. Baik JE, Hong SW, Choi S, Jeon JH, Park OJ, Cho K, Seo DG, Kum KY, Yun CH, Han SH. Alpha-amylase is a human salivary protein with affinity to lipopolysaccharide of Aggregatibacter actinomycetemcomitans. Mol Oral Microbiol. 2013;28:142-53.

19. Fábián TK, Hermann P, Beck A, Fejérdy P, Fabián G. Salivary defense proteins: Their network and role in innate and acquired oral immunity. Int J Mol Sci. 2012;13:4295-320.

20. Filaire E, Dreux B, Massart A, Nourrit B, Rama LM, Teixeira A. Salivary alpha-amylase, cortisol and chromogranin A responses to a lecture: Impact of sex. Eur J Appl Physiol. 2009;106:71-7.

21. Henderson AT, Fisher JF, Blair J, Shea C, Li TS, Bridges KG. Effects of rib raising on the autonomic nervous system: a pilot study using noninvasive biomarkers. J Am Osteopath Assoc. 2010;110:32430

22. Scannapieco F, Torres G, Levine MJ. Salivary alpha-amylase: role in dental plaque and caries formation. Crit Rev Oral Biol Med. 1993; 4:301-7.

23. Pavitra Vibhakar A, Sangeeta Patankar R, Monica Yadav R, Parag Vibbhakar A. Salivary Total Protein Levels and their correlation to Dental Caries. Int J Oral Maxillofac Pathol. 2013;4:13-6.

24. Nagler R, Lischinsky S, Diamond E, Drigues N, Klein I, Reznick AZ. Effect of cigarette smoke on salivary proteins and enzyme activities. Arch Biochem Biophys. 2000;379:229-36.

25. Rai B, Kharb S, Jain R, Anand SC. Biomarkers of periodontitis in oral fluids. J Oral Sci. 2008;50:53-6.

26. Liu J, Duan Y. Saliva: a potential media for disease diagnostics and monitoring. Oral Oncol. 2012;48:569-77.

27. Spielmann N, Wong DT. Saliva: diagnostics and therapeutic perspectives. Oral Dis. 2011;17:345-54.

28. Torres-Lagares D, Recio-Lora C, Castillo-Dali G, Ruiz-de-LeonHernandez G, Hita-Iglesias P, Serrera-Figallo MA, et al. Influence of state anxiety and trate anxiety in postoperative in oral surgery. Med Oral Patol Oral y Cir Bucal. 2014;19:e403-8.

29. Trueba AF, Mizrachi D, Auchus RJ, Vogel PD, Ritz T. Effects of psychosocial stress on the pattern of salivary protein release. Physiol Behav. 2012;105:841-9.

30. Boyle JO, Mao L, Brennan JA, Koch WM, Eisele DW, Saunders JR, Sidransky D. Gene mutations in saliva as molecular markers for head and neck squamous cell carcinomas. Amer J Surg. 1994;168:42932.

31. Zhang L, Farrell JJ, Zhou H, Elashoff D, Akin D, Park NH, Chia D, Wong DT. Salivary transcriptomic biomarkers for detection of resectable pancreatic cancer. Gastroenterology 2010;138:949-57.

32. Rao PV, Reddy AP, Lu X, Dasari S, Krishnaprasad A, Biggs E, Roberts CT, Nagalia SR. Proteomic identification of salivary biomarkers of type-2 diabetes. J Proteome Res 2009;8:239-45.

33. Malamud D. Oral diagnostic testing for detecting human immunodeficiency virus-1 antibodies: a technology whose time has come. Am J Med. 1997;102:9-14.

34. Kountoruras J. Detecting Helicobater pylori. Diagnostic tests for Helicobacter pylori. Gut. 1998;42:900-1.

35. Nicholas BL, Skipp P, Barton S, Singh D, Bagmane D, Mould R, et al. Identification of lipocalin and apolipoprotein A1 as biomarkers of chronic obstructive pulmonary disease. Am J Respir Crit Care Med 2010; 181:1049-60.

36. Zheng H, Li R, Zhang J, Zhou S, Ma Q, Zhou Y, et al. Salivary biomarkers indicate obstructive sleep apnea patients with cardiovascular diseases. Sci Rep. 2014;4:7046. 
37. Schrepf A, Thaker PH, Goodheart MJ, Bender D, Slavich GM, Dahmoush L, et al. Diurnal cortisol and survival in epithelial ovarian cancer. Psychoneuroendocrinology. 2015;53:256-67.

38. Chang YT, Wu CC, Shyr YM, Chen TC, Hwang TL, Yeh TS, et al. Secretome-based identification of ULBP2 as a novel serum marker for pancreatic cancer detection. PLoS One. 2011;6:e20029.

39. Vocka M, Langer D, Petrtyl J, Vockova P, Hanus T, Kalousova $\mathrm{M}$, et al. Trefoil factor family (TFF) proteins as potential serum biomarkers in patients with metastatic colorectal cancer. Neoplasma. 2015;62:470-7.

40. Stiekema A, Boldingh QJ, Korse CM, van der Noort V, Boot H, van Driel WJ, et al. Serum human epididymal protein 4 (HE4) as biomarker for the differentiation between epithelial ovarian cancer and ovarian metastases of gastrointestinal origin. Gynecol Oncol. 2015;136:562-6.

41. Shiiki N, Tokuyama S, Sato C, Kondo Y, Saruta J, Mori Y, et al. Biomarkers. Association between saliva PSA and serum PSA in conditions with prostate adenocarcinoma. Biomarkers. 2011;16:498-503.

42. Streckfus CF, Mayorga-Wark O, Arreola D, Edwards C, Bigler L, Dubinsky WP. Breast cancer related proteins are present in saliva and are modulated secondary to ductal carcinoma in situ of the breast. Cancer Invest. 2008;26:159-67.

43. Turk MJ, Wolchok JD, Guevara-Patino JA, Goldberg SM, Houghton AN. Multiple pathways to tumor immunity and concomitant autoimmunity. Immunol Rev. 2002;188:122-35.

44. Warnakulasuriya S, Soussi T, Maher R, Johnson N, Tavassoli M. Expression of $\mathrm{p} 53$ in oral squamous cell carcinoma is associated with the presence of $\operatorname{IgG}$ and $\operatorname{IgA}$ p53 autoantibodies in sera and saliva of the patients. J Pathol. 2000;192:52-7.

45. Soussi T. P53 Antibodies in the sera of patients with various types of cancer: a review. Cancer Res. 2000;60:1777-88.

46. Buduneli E, Mantyla P, Emingil G, Tervahartiala T, Pussinen P, Barış N, Akıllı A, Atilla G, Sorsa T. Acute myocardial infarction is reflected in salivary matrix metalloproteinase- 8 activation level. J Periodontol. 2011;82:716-25.

47. Mirzaii-Dizgah I, Jafari-Sabet M. Unstimulated whole saliva creatine phosphokinase in acute myocardial infarction. Oral Dis. 2011;17:597-600.

48. Mirzaii-Dizgah I, Riahi E. Salivary troponin I as an indicator of myocardial infarction. Indian J Med Res. 2013;138:861-5.

49. Diercks DB, Kirk JD, Lindsell CJ, Pollack CV Jr, Hoekstra JW, Gibler WB, et al. Door-to-ECG time in patients with chest pain presenting to the ED. Am J Emerg Med. 2006;24:1-7.

50. Xiao H, Wong DT. Proteomics and its applications for biomarker discovery in human saliva. Bioinformation 2011;5:294-6.

51. Hu S, Xie Y, Ramachandran P, Ogorzalek Loo RR, Li Y, Loo JAet al. Large-scale identification of proteins in human salivary proteome by liquid chromatography/ mass spectrometry and two-dimensional gel electrophoresis-mass spectrometry. Proteomics. 2005;5:1714-28.

52. Sabatine MS, Morrow DA, de Lemos JA, Gibson CM, Murphy $\mathrm{SA}$, Rifai N, et al. Multimarker approach to risk stratification in nonST elevation acute coronary syndromes: simultaneous assessment of troponin I, C-reactive protein, and B-type natriuretic peptide. Circulation. 2002;105:1760-3.

53. Miller CS, Foley JD 3rd, Floriano PN, Christodoulides N, Ebersole $\mathrm{JL}$, Campbell CL, et al. Utility of salivary biomarkers for demonstrating acute myocardial infarction. J Dent Res. 2014;93:72S-79S.

54. Mahmood AA, Ibrahim LM. Effects of the examination stress on periodontal health status and salivary IL-1b among Iraqi dental students. J Baghdad Coll Dent. 2013;24:72-8.

55. Usui T, Yoshikawa T, Ueda SY, Katsura Y, Orita K, Fujimoto S. Effects of acute prolonged strenuous exercise on the salivary stress markers and inflammatory cytokines. Jpn J Phys Fitness Sports Med. 2011;60:295-304.

56. Filaire E, Larue J, Portier H, Abed A, Graziella PD, Teixeira A, et al. Lecturing to 200 students and its effects on cytokine concentration and salivary markers of adrenal activation. Stress Health. 2011;27:e25-35.

57. Tsujita S, Morimoto K. Secretory IgA in saliva can be a useful stress marker. Environ Health Prev Med. 1999;4:1-8.
58. Brandtzaeg P. Human secretory immunoglobulins. 3. Immunochemical and physicochemical studies of secretory IgA and free secretory piece. Acta Pathol Microbiol Scand B Microbiol Immunol. 1971;79:165-88.

59. Brandtzaeg P. Secretory immunity with special reference to the oral cavity. J Oral Microbiol. 2013;5. Epub 2013 Mar 11.

60. Demetriou N, Drikos G, Bambionitakis A. Relation between Gingival Fluid and Mixed and Parotid Salivary IgA. J Periodontol. 1978;49:64-6.

61. Ben-Aryeh H, Naon H, Szargel R, Horowitz G, Gutman D. The concentration of salivary IgA in whole and parotid saliva and the effect of stimulation. Int J Oral Maxillofac Surg. 1986;1:81-4.

62. Brandtzaeg P. Human Secretory Inmunoglobulins-VII of Parotid IgA and Other Secretory Proteins in Relation to the Rate of Flow and Duration of Secretory Stimulus. Arch Oral Biol. 1971;16:1295-310.

63. Fábián TK, Hermann P, Beck A, Fejérdy P, Fábián G. Salivary defense proteins: their network and role in innate and acquired oral immunity. Int J Mol Sci. 2012;13:4295-320.

64. Kim KD, Zhao J, Auh S, Yang X, Du P, Tang H, et al. Adaptive immune cells temper initial innate responses. Nat Med. 2007;13:124852.

65. Nater UM, Rohleder N. Salivary alpha-amylase as a non-invasive biomarker for the sympathetic nervous system: current state of research. Psychoneuroendocrinology. 2009;34:486-96.

66. de Santana-Santos T, de Souza-Santos AA, Martins- Filho PR, da Silva LC, de Oliveira E, Silva ED, et al. Prediction of postoperative facial swelling, pain and trismus following third molar surgery based on preoperative variables. Med Oral Patol Oral Cir Bucal. 2013;18:6570.

67. Laskin DM, Abubaker AO, Strauss RA. Accuracy of predicting the duration of a surgical operation. J Oral Maxillofac Surg. 2013;71:446-7.

68. Bello S, Adeyemo W, Bamgbose BO, Obi EV, Adeyinka A. Effect of age, impaction types and operative time on inflammatory tissue reactions following lower third molar surgery. Head Face Med. 2011;7:8. 69. Holland CS. The influence of methylprednisolone on postoperative swelling following oral surgery. Br J Oral and Maxillofac Surg. 1987;25:293-9.

70. Puche F, Martínez Gonzalez JM, Blanco L, Gómez Font R, Donado M. Estudio de los efectos del diclofenaco sódico en el control de la inflamación y trismo postoperatorio del tercer molar inferior. Av Odontoestomatol. 1995;11:225-33.

71. Seymour R, Meechan JG, Blair GS. An investigation into postoperative pain after third molar surgery under local analgesia. Br J Oral Maxillofac Surg. 1985;23:410-8.

72. Meechan R, Seymour A. The use of third molar surgery in clinical pharmacology. Br J Oral Maxillofacial Surg. 1993;31:360-5.

73. Capuzzi P, Montebugnoli L, Vaccaro MA. Extraction of impacted third molars. A longitudinal prospective study on factors that affect postoperative recovery. Oral Surg Oral Med Oral Pathol. 1994;77:341-3.

\section{Conflict of Interest}

The authors have declared that no conflict of interest exist. 